\title{
Study on Personnel Training Mode of Excellent Engineers in Biomedical Engineering
}

\author{
Zhang Kuixing, Jiang Mei, Wei Benzheng, Xu Yunfeng \\ College of Science and Technology \\ Shandong University of Traditional Chinese Medicine \\ Jinan, China \\ E-mail:ql_zkx@163.com
}

\begin{abstract}
The Excellent Engineers Training Project" has put forward some new requirements for the cultivation of talents in our country. It is significant to study the talent training mode of excellent engineer training. According to the training standard and the demands of knowledge ability for the biomedical engineering, this paper has made systematic research on this problem from various aspects, such as the teaching content, curriculum system, practice base construction, the construction of teaching staff, cooperation by production-study-research etc. Practice shows that, the students' comprehensive quality and employment quality has been improved significantly through reform, innovation and the establishment of a new talent training model. It delivered a batch of high-quality technical talent for the medical device industry. At the same time, it improves the school strength and social influence of Biomedical Engineering.
\end{abstract}

Keywords-Biomedical Engineering; Excellent Engineer; Personnel Training Mode; Specialty Construction

\section{INTRODUCTION}

"The Excellent Engineers Training Project" is a great reform project to carry out the objectives of China's "National Plan for Medium and Long-term Education Reform and Development"(2010-2020) and "National Medium and Longterm Talent Development Plan"(2010-2020). It is an important measure to promote China's transition from a big country to powerful country in engineering education. It aims to cultivate a large number of high-quality engineering talents of various types, who have strong innovation ability and adapt to the needs of economic and social development. The implementation of excellent training plan puts forward some new requirements for engineering personnel training in colleges and universities. In 2013, the biomedical engineering specialty in our school was approved for the "The Excellent Engineers Training Project" by the Shandong provincial government. According to the basic requirements of the relevant documents of the project for excellence, combined with the construction of the first batch of "five preeminent featured universities "approved by Shandong provincial government, we continue to update the concept, learn from the advanced experience at home and abroad to carry out the work. By reforming the personnel training mode, optimizing the professional training program and paying attention to cultivating students' innovative ability and practical ability, we achieved remarkable results.

\section{MAIN PROBLEM OF TRADITIONAL PERSONNEL TRAINING}

Biomedical engineering is a new discipline which is closely related to science, engineering, medicine, biology and other disciplines [1]. It has risen in China since the 1970s [2]. At present, medical instruments industry belongs to one of the key industries to encourage for our country. It gives a broad market space for development. Professional talent is the important guarantee to maintain the enterprise's core competitiveness. So with the continuous development of the discipline, part of the engineering colleges and medical colleges used their own academic advantages had established biomedical engineering specialty to cultivate special talents [3]. In this background, in 2006, our university used our own academic advantages to set up biomedical engineering specialty, its educational system is four years and awarded a bachelor's degree in engineering.

In order to cultivate qualified biomedical engineers, we need to consider the cultivation of biomedical professionals from compound, cross, etc., which is in line with the goal of "compound talents training". For a long time, as a medical university to cultivate Chinese traditional medicine talents, our school has accumulated rich experience in the cultivation of the traditional Chinese medicine talents. We have obvious advantages in talent training mode, such as teaching hospitals, teaching and so on. It is easier for us to find medical and clinical practical problems and discover the combination of medicine and Engineering.

But, on the other hand, we don't have enough contact with the enterprise. The internship is usually carried out in the hospital. The engineering practice condition is seriously insufficient. As mentioned above, caused a great obstacle for the implementation of the Excellent Project. 


\section{EXPLORATION ON THE REFORM OF TRAINING MODE OF BIOMEDICAL ENGINEERING}

\section{A. Define the Goal of Talent Training and Develop the Standard of Talent Training}

Biomedical engineering cultivate special talents for the medical device industry [4]. Therefore, we combine with the characteristics and needs of the industry and positioning the training goal of biomedical engineering to cultivating the high quality engineering technicians who can engage in the design, maintenance and research of medical devices.

The establishment of training standards refers to the relevant national and industry standards. We have drawn up "Implementation Matrix of the Training Standard for Undergraduate Excellence Engineer in Biomedical Engineering" and put the knowledge, ability and quality of the professional training goal into theory teaching and practice teaching. Through the integration of courses, projects, internal and external internship and the practice of enterprises to a teaching link, we put the knowledge, ability and quality of the professional training goal into theory and practice teaching link, realize the integration of the professional training goal.

\section{B. Optimize the Program of Talent Training}

In accordance with the requirements of the Ministry of Education and "Training Program for Outstanding Engineers" in Shandong Province, combining characteristics of biomedical engineering industry and market demand characteristics of medical device industry, the principle of "the harmoniously development of knowledge, ability and quality, highlighting the cultivation of practical ability and controllable and sustainable development", we have jointly developed the training program with enterprises [5]. The institute has established the expert groups and working groups for drawing up training program, before drawing up the training program, the Working Group on the one hand to the domestic key universities to investigate, on the other hand to visit enterprises, consulting enterprises on the requirements of talent training. In the process of training program formulation, the institute convened by the enterprise representatives and related industry experts composed of experts demonstration, we have a detailed discussion of the training program and finally draw up a training program for excellent engineer.

Drawing up the talent training program in line with the requirement of "excellent engineer" and strengthening the cultivation of students' engineering practice ability. We increase the proportion of practice courses' credits in training plan, the practice teaching credits accounted for $40 \%$ of total credits. At the same time, the institute implements " $3+1$ "training mode that is the first three years of students in the college to learn the corresponding basic theory and professional basic theories and the last year of students in the relevant enterprises to complete the relevant professional courses and graduation projects. In order to improve the practical ability of students and strengthen the training of engineering practice, the students have practical courses each semester and be arranged two weeks of summer internship in the annual summer vacation in their first three years.

\section{Reform Curriculum System and Teaching Content}

The excellence program has made clear requirements for excellence engineers in terms of knowledge, competence and quality [6].Curriculum system and teaching content' s reform is a critical and challenging task to complete the training of excellent engineers [7].

In the process of reform, we take the principle of "consolidating the theoretical foundation, strengthening the practical ability and stressing the innovation of thinking", dividing the professional curriculum system into general education, basic classes of disciplines, professional education, personality cultivation, etc. In large class, the institute optimizes and reorganizes curriculum according to the principle of curriculum relativity, especially in the professional curriculum library, set up the curriculum group according to the principle of "content related and cohesion". The curriculum group is composed of teachers with relevant field knowledge and rich teaching experience to ensure the integrity and consistency of the curriculum system, for example, in the course of the construction of professional curriculum system, "Medical image processing curriculum group" and "medical instrument curriculum group" were established. The construction of curriculum group adheres to the principle of running from theory to application, such as "medical instrument curriculum group" through the "Biomedical Signal Detection and Sensor", "Biomedical Signal Processing", "Medical Instrumentation Principles and Design", etc. "Biomedical Signal Detection and Sensor" is mainly based on the collection of biomedical signals, so that students have a preliminary understanding of the characteristics of biomedical signals, "Biomedical Signal Processing" mainly explains the signal processing method, the two are the basis of "Medical Instrumentation Principles and Design". Through the coherence of teaching and learning, so that students master the basic knowledge of medical instrument design, whether form the whole or part of the medical instrument design has a full understanding. In the course of teaching, we should make full use of the example teaching, enhance students' innovative ability to meet the requirements of excellence engineer training.

\section{Construction of Teaching Staff with Engineering Education Ability}

The excellence program requires the construction of a certain project experience and a part-time combination of highlevel teachers [8]. Biomedical engineering is a new professional, started late, its time is short compared with the traditional professional development. Professional teachers are mostly form other professional careers to create a rich engineering practice ability and background of teachers seriously inadequate. However, the practical operability of the cultivation of biomedical engineering professionals is very strong, teachers engage in this field not only need to have a wealth of theoretical knowledge and strong practical experience, but also to be able to combine the teaching work with scientific research and promote the improvement to teacher' abilities through scientific research [9].

The first is to strengthen the teacher's basic theory and practical knowledge training, combining with the construction of professional master's degree, we actively encourage the 
horizontal joint between the master's tutor and the outside enterprises, stimulate and encourage the young teachers who are engaged in the undergraduate course teaching. Through the cooperation with the enterprises or hospitals, we refine from practice and integrate into the teaching, at the same time, inviting outside instructors to participate in undergraduate teaching, putting the practical problems of enterprises into the classroom to cultivate students' interest in learning; Second, strengthening the study and research, we arrange professional teachers to study and research in key universities or enterprises at home and abroad and organize professional teachers to study in enterprises or hospitals in their holiday. This can strengthen the combination of theory and practice. The third is to continuously optimize the talent team, so as to form a reasonable structure, scientific research and teaching complementarily and in line with the training of excellent talent teaching team.

\section{E. The construction of teaching system of innovation and practice}

The core of Excellence program is to cultivate students' ability of engineering practice and innovation. The cultivation of practical ability depends on the practice teaching system, so the cultivation of excellent talents and construction of practical teaching system is the only way [10].

Reform the content of experimental teaching. In the formulation and implementation of teaching plan, we fully embody the students' engineering practice ability and innovation ability, rationally utilize the resources in the class, outside class, school, outside school and create all conditions for students to practical training opportunities. On the basis of reform of the theory course, the traditional confirmatory experiment is changed into the designing and comprehensive experiment. We increase the link of the course design and strengthen the examination and training of the engineering practice ability. At the same time, we also strictly designate the students' internship standards in each stage of the school period and revise the internship syllabus.

Strengthen the construction of laboratory in the school. The institute is guided by the principle of conserving resources, apply for actively and increase the experimental funding. On the basis of the laboratory of basic medical experimental platform and physics electronic platform, we purchase professional teaching equipment and establish biomedical testing and sensor laboratories, biomedical image processing laboratories, biomedical instrumentation laboratory and other specialized teaching laboratories. At the same time, we also establish an innovative laboratory that provides competition opportunities and experimental sites for students. The establishment of virtual medical imaging equipment laboratory makes the students familiar with the structure and principle of the commonly used image equipment and lay a good foundation for entering the enterprise internship stage.
Expand actively the enterprise internship base. On the basis of maintaining the advantage resources of the affiliated hospital of the school, we actively strengthen the development of the practice base of enterprises and meet the needs of the students' " $3+1$ "training mode to the enterprise internship base. So we have signed a cooperation agreement with Shanghai Kedu Medical Group and Jining Hewlett-Packard software to research and production cooperation.

Play the advantage of scientific research of school teachers and building the second classroom. By encouraging students to participate in teachers' scientific research projects, declaring students' innovative training plans and participating in various competitions, the aim is to improve students' innovative ability.

Actively introduce out-of-school high-quality resources to provide students with academic reports. Using teachers' scientific research and cooperative relations in to invite experts form domestic and overseas make academic reports, so that teachers and students can understand the frontier direction of current and future research and the demand of the society for talents and so on.

\section{F. Establish perfect organization management system}

In order to ensure the smooth implementation of the excellent project, the school established the leading group headed by the president as the head of the team, the vice president in charge of the teaching as the vice leader of the "excellent engineers training project". The leading group is responsible for formulating school related policies, coordinating the various aspects of the relationship, ensuring the input of teaching funds, and strengthening the construction of teaching staff. The dean of Education Office set up a special management organization "excellent engineer education and training office", which is responsible for the implementation of the pilot work such as school enterprise cooperation, student selection and related coordination work etc. The secondary schools set up excellent engineers training working group and professional construction committee. The working group is responsible for drawing up the training standards and training program, studying the recruitment, selection and diversion way and undertaking teaching conditions construction, quality assessment, student status management, student management and other detailed works in the process of the implementation plan. which is responsible for the specific work under the leadership of the school leading group such as drawing up the professional training standards and specialty cultivation programmer, organizing and implementing teaching tasks and other specific work. The professional construction committee is composed of more than 9 experts, at least $40 \%$ of whom are from cooperative enterprises. The professional construction committee is responsible for formulating training objectives, teaching plans, curriculum system, assessment methods and evaluation standards. 


\section{THINKING AND SUGGESTIONS}

\section{A. Improve the requirements for professional credits}

Biomedical engineering and medical device industry emphasize the intersection of medicine and engineering and require the mastery of both basic theories and knowledge. The study of specialized courses includes not only the science and technology courses such as the microcomputer principle, the automation control, but also the medical courses such as medical physics, medical imaging, anatomy, physiology, etc. The institute makes up for the shortage of theory and practice of engineering or medicine by increasing students' credit requirement during school and prolonging the time of theoretical and practical study.

\section{B. Build a consistent pattern of training for excellent undergraduates and engineering graduates}

Student internship generally arranged in the last year. Because of the social and industrial characteristics of higherlevel talent demand, some students choose to obtain graduate and practice simultaneously. Therefore, through the implementation of streaming training to the senior students to enter the enterprise internship, students accumulate certain practical experience and more conducive to the training of their postgraduate stage.

\section{Improve relevant policies, encourage enterprises to participate in school enterprise cooperation}

School enterprise cooperation is one of the main ways of training excellent engineers. But the related enterprises are not motivated enough to participate in the cooperation. The main reason is it will increase the operating costs of enterprises. As the main body of market economy, enterprise takes profit as its main management objective. Enterprises involved in personnel training is a kind of social responsibility. It should be the way for enterprises to obtain economic benefits and social identity. At present, enterprises do not have a direct interest In the process of personnel training. The risk of liability and the expenses is great. To a certain extent, it is not conducive to improve the enthusiasm of enterprises. Enterprises are not willing to take part in school enterprise cooperation deeply. Therefore, our government should draw up the relevant policies, vigorously support the participation of enterprises, give clear encouragement and preferential policies for enterprises to participate in and promote them to participate in training of outstanding engineers.

\section{SUMMARY}

In recent years, biomedical engineering industry has developed rapidly in our country, which urgently needs a large number of professional and technical personnel with high level of technology and strong innovation ability. The implementation of the excellent plans has provided the talent guarantee for the industry development, we have accumulated some experience in a series of reform and practice and has created the condition for the successful implementation of the excellent plan.

Through the reform of personnel training mode, cooperation and exchange with enterprises, cultivating students' engineering ability and innovation consciousness, it makes the students have strong competitiveness in practice, recognized by many enterprises. The graduates are in good employment. Many students have become the backbone of enterprises and play very important role. Based on the work done in the reform of personnel training mode, the strength of the biomedical engineering discipline has been continuously enhanced, and the biomedical engineering specialty has been assessed as the provincial key construction specialty in 2016 .

\section{ACKNOWLEDGMENT}

The results of this research are supported by Shandong University of Traditional Chinese Medicine Educational Research Project and Shandong provincial higher education institutions and Shandong University of Traditional Chinese Medicine young Key Teachers' domestic visiting scholars project funding.

\section{REFERENCES}

[1] Wang Nenghe, Zou Weidong and Li Yibing. "Research and practice of application-oriented undergraduate training system for biomedical engineering majors (in Chinese)" $[\mathrm{J}]$. Journal of mathematical and pharmaceutical science, 2008, 21(5):627-629.

[2] Hu Xingbin. "Discussion on present situation and prospect of biomedical engineering (in Chinese)" [J]. Medical and health equipment, 2004(9):99-101.

[3] Dong Xiuzhen. "Introduction to biomedical engineering (in Chinese)" [M].Xian: Four military medical university press, 2004:27.

[4] Lv Jie, Cao Jinfeng, Liu Yang and Zhang Peiming. "Thinking about the application-oriented biomedical engineering specialty in medical device industry construction (in Chinese)" [J]. Advances in biomedical engineering, 2017, 38(1):60-62.

[5] Feng Tianliang, Wu Yingjiang and Zhao Yun. "Exploration and construction of talents training scheme for excellent medical information specialty (in Chinese)" [J]. Chinese medical education technology, 2014, 28(6):601-604.

[6] Lin Jian. "Development of the general standard of "education and training program for excellent engineers" (in Chinese)" [J]. Research on higher engineering education, 2010, (4):21-29.

[7] Lin Jian. "Curriculum system and teaching content reform oriented to "excellent engineer" (in Chinese)" [J]. Research on higher engineering education, 2011, (5):1-9.

[8] Ruan Mingjun. "Comparative study of Chinese and Vietnamese distinguished engineers (in Chinese)" [D].Kunming: Kunming University of Technology, 2014:21-22.

[9] Huang Xiaomin. "Exploration on the training mode of applied undergraduate talents for biomedical engineering specialty (in Chinese)" [J]. Adult Education in China, 2015, 8:162-263.

[10] Song Peiwei. "Strengthen the reform of practice teaching and train the excellent engineer (in Chinese)" [J]. Heilongjiang Education, 2011, (6):4-8. 